\title{
RECURSOS TURÍSTICOS Y DESARROLLO SOSTENIBLE EN LA RUTA E-80: SALAMANCA-AVEIRO. ASPECTOS GEOGRÁFICOS
}

\author{
POR \\ EUGENIO GARCÍA ZARZA
}

\begin{abstract}
«Los que hablan de Castilla y León, como si no fuesen más que peludos parameros, desnudos de árboles, abrasados por los soles y hielos, áridos y tristes, no han visto estas tierras sino al correr del tren y muy parcialmente. Donde en estas mesetas se yergue una Sierra, tened por seguro que en el seno de ella se esconden valles que superan en verdor, en frescor y en hermosura a los más celebrados del litoral Cantábrico.»

M. De Unamuno: Por tierras de Portugal y España
\end{abstract}

\section{Aspectos generales}

El trabajo que presento forma parte de una línea de investigación sobre temas turísticos, dentro de las actividades investigadoras y docentes, como Catedrático de Geografía Humana y del Turismo en la Universidad de Salamanca. Los trabajos sobre esta temática se centran, sobre todo, en los recursos turísticos relacionados con Salamanca, Castilla y León y territorios cercanos de Portugal. Las frecuentes y

Eugenio García Zarza. Departamento de Geografía Humana, Universidad de Salamanca.

Estudios Geográficos

Tomo LX, n. ${ }^{\circ} 235$, abril-junio 1999

$$
-271-
$$


fructíferas relaciones con colegas portugueses, en el ámbito turístico, me animaron a realizar el presente trabajo sobre Recursos Turísticos y Desarrollo Sostenible en la E-80: Salamanca-Aveiro. Como es sabido, dicha Ruta es el principal Eje de Comunicaciones para enlazar por tierra, directamente, Portugal con Centroeuropa, Lisboa con París.

A lo largo de tan importante ruta hay muchos, importantes y variados recursos turísticos, cuyo grado de conocimiento y explotación es muy diverso y, por lo general, más escaso de lo que se merece la calidad e interés de los mismos. Estas características de los recursos turísticos de dicha ruta quizás es más significativo en las tierras cercanas a la frontera hispano-portuguesa, cosa que también le ha ocurrido en otros sectores y actividades socioeconómicas, razón por la cual, el subdesarrollo, la emigración, actualmente, la despoblación y el alto grado de envejecimiento es otro rasgo más, y también destacado, de tales tierras. Esta es una de las razones por las que el estudio adecuado de sus recursos turísticos, para un mejor aprovechamiento de los mismos, adquiere más interés y actualidad. Se trata, además, de una condición previa para que tales recursos sean una fuente de ingreso para la economía de las tierras en las que se encuentran y que mejore la situación de la población que vive en ellas.

\section{Importancia socioeconómica de la actividad turística}

La actividad turística es hoy un sector económico importante a escala mundial, la tercera tras la petroquímica y la del automóvil. En algunos espacios, como en Europa Occidental, Norteamérica y diversas zonas de otros territorios, constituye actualmente una importante fuente de ingresos. Según la OMT, unos 617 millones de personas participaron en dicha actividad a escala internacional en 1997; es decir, salieron de su país para visitar otros diferentes por causas o razones turísticas. La cifra se incrementa a 1.600 millones, un tercio de la población mundial, en el caso del Turismo Nacional, esto es, el realizado dentro de cada país por sus habitantes. Las cifras anteriores confirman algo bien conocido desde hace tiempo en España, la importancia del turismo como destacada actividad económica y fuente de ingresos.

Las repercusiones socioeconómicas de tan importante desplazamiento de personas por razones o motivaciones turísticas, están en

$$
-272-
$$


consonancia con las citadas antes. El caso de España es buen ejemplo de ello, pues no en vano es actualmente la segunda potencia mundial turística después de Estados Unidos. El año 1996 recibió 63 millones de visitantes de los que unos 45 fueron turistas que aportaron 3,5 billones de pesetas, cuantía cercana al 10\% del PIB y dio ocupación al $9 \%$ de su población activa, similar al que está ocupado en el sector primario, tan importante siempre en la economía española.

Además de la Importancia socioeconómica que tiene hoy el turismo en el mundo y del que el caso español es bien significativo, hay que destacar otras interesantes características del citado fenómeno. Tal es el caso de su acelerado crecimiento desde los años cincuenta hasta hoy. Aunque el turismo es una actividad tan antigua como el hombre, sin embargo ha sido en el siglo xx y concretamente, después de la firma del Tratado de Roma en 1957, cuando ha tenido un crecimiento acelerado, espectacular. En 1950, hace menos de medio siglo, sólo participaron en esta actividad a escala mundial unos 25 millones, esto es, poco más del $4 \%$ que actualmente. El ritmo de incremento de la actividad turística desde entonces ha sido realmente espectacular, tanto en su cuantía como en la importancia socioeconómica. Algo similar se puede decir respecto a la tendencia que tendrá en los próximos años. Se estima que, a escala mundial, el número de turistas se incrementará a un ritmo medio del $3,5 \%$ anual y, en mayor medida, lo harán los ingresos, cuantías ambas muy superiores a las de cualquier otra actividad socioeconómica de tanta importancia. Quiere esto decir que, para el cercano año 2.000, el contingente turístico internacional será de unos 650 millones y para el 2.010 superará los 850 , confirmándose el acelerado y espectacular incremento mantenido hasta hoy. Este importante incremento del Turismo Internacional parece ser que será superado por el que mantenga el Turismo Interior, con lo que se confirma que la importancia actual del sector se mantendrá en los próximos años.

Los datos anteriores sobre la evolución reciente y tendencia futura del Turismo Internacional, al que pertenece una parte importante del existente en la E-80: Salamanca-Aveiro, confirman la importancia del fenómeno, su generalización por todo el mundo y creciente aceptación. Pero no conviene olvidar el Turismo de Interior o Cultural, realizado dentro de cada país, en regiones no costeras y con predomonio de recursos diferentes al del Sol y Playa, cosa que sucede en el caso presente. Según datos de la OMT, el 15\% de los participantes en el Turismo In- 
ternacional y en mayor cuantía los del Nacional, prefieren los variados recurso existentes en las regiones del interior a los de las zonas costeras. La evolución mostrada en los últimos años por este tipo y la tendencia que manifiesta para los próximos, revelan un crecimiento incluso superior al ya muy importante del Turismo de Sol y Playa. Es decir, cada día son más los turistas que se decantan por recursos como los existentes en estas tierras de la E-80: ciudades monumentales, paisajes rurales diversos e interesantes, peculiar arquitectura popular, monumentos, gastronomía, folclore y hospitalidad de las gentes, su modo de vida y otros muchos recurso del mundo rural. Pero no basta con tener recursos turísticos si son desconocidos, carecen de la infraestructura y promoción adecuadas y no tienen el grado de aprovechamiento que merecen por su interés, calidad y variedad, cosa que sucede en el caso presente. Por ello es tan necesario estudiarlos y darlos a conocer.

Es interesante conocer estas características del Turismo en general y del Cultural o de regiones interiores como la de la Ruta E-80, para actuar en consecuencia y no dejarse llevar por la creencia de que a todo el mundo sólo le interesa el turismo de Sol y Playa o que los recursos existentes aquí son los mejores dentro del Turismo de Interior. Es cierto que aquél sigue siendo el mayoritario y masivo, pero no el único ni el que tiene ahora el mayor ritmo de crecimiento. También hay que saber que recursos turísticos como los que hay en tierras como las de Salamanca y las Beiras lusitanas, tampoco están entre los peores, sino que ahora gozan de las preferencias de una población cada día más numerosa, cuando éste reúne las condiciones adecuadas de promoción, presentación, buenas comunicaciones y servicios de hostelería apropiados. Por todo ello, es necesario conocer las características de nuestros recursos, sus posibilidades y limitaciones, así como el estado actual de las infraestructuras y servicios y actuar en consecuencia, con realismo, entusiasmo, pragmatismo, unión de fuerzas y eficacia.

Las perspectivas socioeconómicas para una parte importante de la población y la generalización del modo de vida en el que el turismo es ya algo casi fundamental, básico, una necesidad, permiten aceptar como seguras las estimaciones citadas sobre la evolución de la actividad turística a corto y medio plazo. Este aspecto del acelerado, casi espectacular, crecimiento de la actividad turística en un futuro próximo, es muy importante tenerlo presente, para poner nuestros recursos en la forma que sean atractivos y competitivos, planificar con tiempo su creciente 
desarrollo, preparar el personal apropiado y las instalaciones necesarias para atender adecuadamente a los turistas. Además, para evitar o contribuir a reducir la incidencia negativa de problemas de todo tipo que causa una actividad tan importante, generalizada, dinámica e influyente en muchos aspectos medioambientales y socioeconómicos como es la actividad turística.

\section{La actividad turística y el desarrollo sostenible}

En los años cincuenta y sesenta la preocupación mayor de los responsables políticos en el aspecto económico, era impulsar el desarrollo cuantitativamente, esto es el Desarrollo Cuantitativo, incrementar el PIB nacional, y la renta per cápita de la población. Era muy escasa la preocupación o se le prestaba poca atención al coste social y medioambiental que suele producir todo desarrollo, las desigualdades y desequilibrios socioeconómicos sectoriales o regionales que pudiera ocasionar o la destrucción de los recursos explotados, en este caso los turísticos, que esto pudiera producir. Es evidente que predominaba el interés por la cantidad, sin importarle los costes sociales, las injusticias y diferencias sectoriales y regionales que llevaba consigo tal tipo de desarrollo. Actualmente la situación ha cambiado bastante, entre otras razones porque hay conciencia de los importantes problemas socioeconómicos que lleva consigo el Desarrollo Cuantitativo citado antes y es creciente el interés por el Desarrollo Integral, esto es, de todos los sectores económicos o del mayor número posible de ellos y de todas las regiones de un país, procurando reducir los problemas medioambientales al máximo, también las diferencias sectoriales y regionales y que toda la población se beneficie, en el mayor grado posible, de las mejoras socioeconómicas conseguidas.

Esto está en consonancia con el interés que ha adquirido el denominado Desarrollo Integral, conocido también como Desarrollo Sostenible, tan en boga hoy. Esto es, la explotación de los recursos, en este caso los turísticos, al mayor nivel posible, en beneficio de la economía y bienestar de la población, sin poner en peligro la existencia de aquéllos y que, sin deterioro del medio ambiente, se asegure su continuidad y aprovechamiento similar por las generaciones futuras. En efecto, la actividad turística y mayormente la del Turismo de Interior, que es el 
predominante en la Ruta E-80: Salamanca-Aveiro, puede ser uno de los mejores procedimientos para impulsar el desarrollo, no sólo de sus recursos turísticos sino de otros que, sin el turismo, tendrían pocas opciones de poder desarrollarse e incluso de existir. El turismo no sólo demanda servicios, sino que produce un incremento del consumo de productos alimenticios, artesanales y de otros muchos tipos, así como de servicios diversos, muchos de los cuales pueden y deben ser producidos en la propia región, con el consiguiente beneficio para los sectores de procedencia.

Está fuera de toda duda que, tanto el sector primario como la construcción, la recuperación y mantenimiento del patrimonio monumental y paisajístico, la construcción y mantenimiento de las comunicaciones, la artesanía y ciertas industrias agroalimentarias y otras más de diversa índole y servicios muy diversos, existentes a lo largo de la E-80, pueden beneficiarse con el desarrollo turístico, además de hacerlo las actividades turísticas propiamente dichas. De esta forma es como el turismo puede y debe ser un importante factor para impulsar el Desarrollo Sostenible de las tierras cruzadas por la Ruta E-80: Salamanca-Aveiro.

Son muchas las características generales que, en relación con lo anterior y a modo de resumen de ellas, pueden señalarse de la actividad turística, de su importancia para el desarrollo socioeconómico de las tierras y sus gentes, aplicables en el estudio que se haga de la misma en cualquier espacio y en particular en las tierras de la Ruta E-80: Salamanca-Aveiro. Destacaré las siguientes:

a) Importancia actual e interés creciente de la actividad turística hasta ser hoy una fuente de ingresos en la economía de muchos países y regiones. Dentro de ella, cada día es mayor la participación del Turismo de Interior, confirmado con los datos de la OMT, con un ritmo de crecimiento superior al del Turismo Internacional y en mayor cuantía dentro del Nacional. Todos ellos muestran una tendencia claramente creciente, y a corto y medio plazo, lo cual es alentador y debe servir de estímulo para trabajar aprovechándose de tal situación y tendencia. Sabemos que en las tierras de Salamanca y las Beiras lusitanas, cruzadas por la Ruta E-80: Salamanca-Aveiro hay recursos turísticos muy variados, con claro predominio de los de Interior, lo que debe ser conocido y tenido muy en cuenta.

$$
-276-
$$


b) La actividad turística, en cualquiera de sus manifestaciones, tanto en la de Sol y Playa como en la Cultural o de Interior, cuando se explota racionalmente, es uno de los mejores factores para el Desarrollo Integral o Sosienible. Cada día son más evidentes las grandes posibilidades que tiene el turismo para ser una actividad que favorezca, como pocas, dicha forma de desarrollo, con toda la importancia socioeconómica que esto tiene. Esto es, ser una actividad económica con relativa y a veces destacada importancia en un lugar, región o país y, además, contribuir de manera eficaz y positiva, al desarrollo de otras muchas actividades, algunas de las cuales tendrían pocas posibilidades de hacerlo sin la intervención del fenómeno turístico.

c) Por último, destacar que el desarrollo de la actividad turística debe servir para contribuir a conservar los propios recursos, evitar su deterioro o desaparición, con lo que se pondría fin a la actividad turística. Además, debe tener también como objetivo fundamental, servir para desarrollar dicho sector, la construcción de instalaciones adecuadas y los servicios que requiere la misma. También para impulsar el de otras que están o pueden estar relacionadas con él, como el mantenimiento, la recuperación y desarrollo de cierto cultivos y productos para atender el turismo, el impulso de la artesanía, gastronomía, fiestas populares y la conservación y, no pocas veces, recuperación del patrimonio monumental y paisajístico, entre otras cosas. Todo ello contribuirá a un desarrollo más completo e importante de la economía de estas tierras y mejoras en el nivel de vida y el bienestar de la población.

\section{Recursos turísticos de la Ruta E-80: Salamanca-Aveiro}

Los comentarios anteriores, aunque breves, han puesto de manifiesto la importancia creciente y acelerada de la actividad turística en el mundo. Sabemos que en España y Portugal registra gran desarrollo, aunque el mayor impulso se deba al turismo de Sol y Playa. Ambos países cuentan con muchos y variados recursos turísticos y factores favorables a su aprovechamiento que explican el gran desarrollo e importancia de dicha actividad. De forma general podemos agrupar los recursos en dos grandes tipos: Sol y Playa y Turismo de Interior. Mientras que el primero tiene como principales recursos los dos citados en su denominación, en el segundo la diversidad de recursos es la nota característica, 
recibiendo nombres muy diferentes, según el recurso más aprovechado o predominante. La distribución y el grado de desarrollo, en las regiones que poseen uno $u$ otro, presenta grandes diferencias, por causas muy diversas, aunque son muchos menores que hace un par de décadas, en que la mayor parte de los turismos de interior actuales apenas tenían importancia. En el caso presente, las causas han sido bastantes y muy importantes, tales como el desconocimiento de los propios recursos turísticos, la falta de interés, escasez de inversiones y promoción, así como las deficiencias en las infraestructuras necesarias.

El territorio estudiado, tierras de la Ruta E-80: Salamanca-Aveiro, cuenta con ambos tipos de recursos turísticos, aunque con claro predominio de los de Turismo de Interior. El grado de desarrollo, de aprovechamiento de unos y otros, está lejos de la calidad, variedad e interés de los recursos y posibilidades existentes. Como ha sido habitual en España y Portugal, también en estas tierras los recursos turísticos más conocidos y mejor explotados, dentro del escaso desarrollo del sector, lo han sido los del turismo de Sol y Playa, seguidos por los del patrimonio histórico-monumental. Sin dejar de lado la promoción de tales recursos, antes al contrario, apoyando su fomento y desarrollo, es indudable que se debe volcar el mayor esfuerzo posible en el conocimiento, promoción y desarrollo de los recursos del Turismo de Interior, por ser más numerosos, variados y beneficiar a más gente que se halla en situación socioeconómica bastante precaria. Además, es seguir un poco la corriente predominante no sólo en los países desarrollados sino en todo el mundo, de interesarse por impulsar el Turismo de Interior, cada día con mayor interés y clientela.

Sin alegrarnos por el menor crecimiento del Turismo de Sol y Playa, sí nos satisface conocer el mayor dinamismo del Turismo de Interior. Esto debe ser un estímulo para trabajar en el desarrollo turístico de la Ruta E-80: Salamanca-Aveiro, aplicando la política turística adecuada a sus características, exigencias y estado en que se halla, no sólo el sector turístico sino la economía de estas tierras. No es utópico ni exagerado decir que estas tierras cuentan con recursos y posibilidades para que el turismo pueda ser una actividad socioeconómica interesante, bastante más destacada de lo que es en la actualidad. Debidamente promocionada puede ser una importante fuente de ingresos para la maltrecha economía de estas tierras y para mejorar el nivel de vida de su escasa y envejecida población. 
Para ello, es condición previa, indispensable, conocer los recursos turísticos existentes, sus problemas y posibilidades para aprovecharlos adecuada y racionalmente y conocer las repercusiones que derivará de ello para la economía, población y medioambiente. De lo contrario, continuarán las cosas como hasta ahora, los recursos turísticos seguirán escasamente explotados, lo cual no es óbice para que pueda peligrar su integridad o sufran daños irreparables. Por ello, su aportación a la economía de la zona seguirá siendo escasa, muchas veces nula, por el desconocimiento de ellos, por las graves deficiencias de las comunicaciones y los servicios. Por este motivo la economía y nivel de vida seguirán por debajo de la media nacional, la población joven marchándose, la despoblación y el envejecimiento incrementará su negativa influencia y se mantendrá el estancamiento o escaso dinamismo socioeconómico en las tierras del tramo de la Ruta E-80: Salamanca-Aveiro, como la característica más destacada. Sin ánimo de ser exhaustivo, en un análisis rápido y sencillo, destacan los siguientes recursos turísticos en las tierras de la citada ruta.

1. ${ }^{\circ} \quad$ El primer tipo de recursos turísticos del territorio estudiado corresponde a las Características físicas del territorio: morfología, clima, vegetación, ríos, costas, playas y paisaje en general. Como principales rasgos en este primer bloque de recursos turísticos destacan la belleza, interés y variedad de los paisajes. Sabemos que la Ruta E-80: Salamanca-Aveiro cruza las tierras centro-oeste de la Península Ibérica, pertenecientes a las cuencas del Duero, Tormes, Águeda, Vouga y Mondego y a la provincia de Salamanca y varios Distritos de las Beiras lusitanas. La parte salmantina forma un altiplano que va descendiendo hacia el $\mathrm{O}$, ocupado, primero por las campiñas cerealísticas y después por montes de encinares y robles con un paisaje sencillo, sobrio pero interesante y en el que destacan las explotaciones del ganado bravo, las famosas dehesas salmantinas. La belleza de estos paisajes ha sido reconocida hace tiempo por muchas gentes, como lo acreditan los versos que le han dedicado autores como A. Machado, J. M. ${ }^{a}$ Gabriel y Galán y M. de Unamuno, al que pertenecen estos versos: Sobre este mar de encinas castellanos / los siglos resbalaron con sosiego, / lejos de las tormentas de la historia, / lejos del sueño / que a otras tierras la vida sacudiera; / sobre este mar de encinas tiende el cielo / su paz engendradora de reposo, / su paz sin tedio. / Sobre este mar que guarda en sus entrañas 
/ de toda traición el manadero, / esperan una voz de hondo conjuro / largos silencios.

Por el S el territorio citado se eleva y accidenta por la presencia de diversos sectores del Sistema Central, tales como las Sierras de Béjar, Francia, Gata, Estrella y Caramulo. El interés turístico se acrecienta con la aparición de características paisajísticas y recursos turísticos nuevos y diferentes, derivados de la existencia de fracturas geológicas, diversidad morfológica, afloramiento del roquedo e interesantes formas de modelado glaciar. En el mismo sentido contribuye la mayor acción erosiva de la red fluvial que nace o cruza los espacios montañosos y otras zonas de la región estudiada, tales como el Duero, Tormes, Yeltes, Águeda, Côa, Mondego, Dâo y Vouga. Unas veces forman profundos encajamientos, verdaderos cañones como en Los Arribes y otras fértiles valles o Riberas, como la del Tormes a su paso por Salamanca, pero todos con gran interés paisajístico y turístico. Son también muchos los testimonios de viajeros que han recorrido estas tierras y han quedado prendados de la belleza, variedad e interés de sus paisajes.

2. ${ }^{\circ} \quad$ El clima, como el relieve, va cambiando de $\mathrm{E}$ a O, y en el mismo sentido lo hacen la vegetación y los cultivos, acrecentándose el interés y la diversidad paisajística por tales motivos. Los Encinares salmantinos ceden su lugar a otras especies vegetales que cubren profusamente y con gran variedad e interés paisajístico las tierras portuguesas, robledales, pinares y en la Región del Dâo, sus famosos viñedos. Por todo ello, el paisaje adquiere rasgos nuevos y diferentes a los de las tierras salmantinas, pero igualmente interesante y de gran belleza e interés. La parte occidental y costera del territorio recorrido por la E-80: Salamanca-Aveiro, es baja y forma una llanura litoral en la que agua y tierra se confunden, en un paisaje de gran belleza y fantasía, con las típicas e interesantes formas y paisajes de estas tierras: llanuras litorales, albuferas, estuarios, barras litorales, dunas costeras y largas playas en claro contraste paisajístico y extraordinario complemento de las tierras del interior. La diversidad paisajística de las tierras de la Ruta E-80 es evidente y constituye un interesante recurso turístico, muy poco conocido, incluso por la propia población y escasamente aprovechado, en general.

3. ${ }^{\circ}$ A todo lo expuesto y, estrechamente relacionado con lo anterior, hay que unir los balnearios existentes en estas tierras, relacionados con las fracturas geológicas del territorio. Se hallan en zonas de gran belleza paisajística, a veces paradisíaca, como es el caso de San Pedro do Sul y 
en tramos fluviales con valles muy interesantes, por su morfología, vegetación y cursos de agua. Están siendo explotados desde hace milenios $\mathrm{y}$, tras unos cuantos años de crisis, por no estar de moda, han vuelto a adquirir hoy gran auge, con un elevado grado de explotación. Tal es el caso de los de Ledesma, Retortillo, Cavaca, Felgueira, Alcafache, Carvalhal y San Pedro do Sul, entre otros. Se trata de un recurso turístico que, tras un período de decadencia y escasa aceptación social, ha vuelto a recuperar con claro auge, su anterior interés e importancia dentro de la actividad turística.

4. ${ }^{\circ}$ Pero si interesantes y variados son los recursos turísticos derivados o relacionados con el medio natural, más lo son los que tienen al hombre, a las gentes que han vivido en estas tierras como protagonista. La evolución histórica de estas tierras se caracteriza por la antigüedad e importancia del poblamiento y por su destacada participación en muchos períodos de la historia peninsular, desde los primeros asentamientos humanos. Comenzó con las importantes aportaciones, que han llegado hasta nuestros días, de la Cultura de los toros y verracos en Salamanca y siguió con la oposición a los romanos capitaneados por el legendario e importante personaje de Viriato. Después siguió durante la agitada Edad Media, en la que estas tierras tuvieron una destacada participación en las tensas relaciones entre Castilla y Portugal. Recuerdo y consecuencia de aquellos agitados tiempos y de los enfrentamientos hispano-portugueses, son las interesantes construcciones militares que hay a uno y otro lado de la frontera. Destacan por su interés, aunque no sean las únicas, las de Almeida, Ciudad Rodrigo, Fuerte de la Concepción, Figueira de Castelo Rodrigo y S. Felices de los Gallegos.

Las aportaciones en el mundo de la Cultura y el Arte también han tenido una destacada importancia con la Universidad de Salamanca y su importante, secular y actual proyección internacional por España e Iberoamérica. Todo ello, evolución histórica y destacada participación en la misma, ha dejado su testimonio y manifestación material en la abundancia, diversidad, calidad e interés del patrimonio históricocultural y riqueza cultural que atesoran los pueblos y ciudades de las tierras recorridas por la E-80: Salamanca-Aveiro. Esto constituye hoy un destacado e importante recurso turístico para las mismas. La simple relación de lo más interesante, desde la época prerromana hasta nuestros días, alargaría en exceso este trabajo. Pero queda de manifiesto citando las ciudades con mayor riqueza e interés histórico-artístico: Sa- 
lamanca, Alba de Tormes, Ciudad Rodrigo, Almeida, Guarda, Aguiar da Beira, Mangualde, Neilas, Viseu y Aveiro, por citar sólo las más importantes, pero no las únicas.

5. ${ }^{\circ}$ Estas tierras cuentan con otros interesantes recursos turísticos, además de los citados y estrechamente relacionados con las características naturales del territorio, evolución histórica, recursos existentes y la población que ha vivido y vive en ellas. Tal es el caso de la Gastronomía, con gran variedad y calidad, pues cuenta con extraordinaria materia prima, carnes, pescados, vinos y dulces, producidos en estas tierras y sabiamente elaborados por sus gentes. La simple relación de lo más importante e interesante en esta cuestión también alargaría en exceso la exposición, por el elevado número de productos y platos típicos, la calidad e interés de los mismos, pero quede constancia de su destacada importancia e interés dentro de la actividad turística y como recurso destacado dentro de la misma en estas tierras. A modo de ejemplo podemos citar los productos ibéricos salmantinos y los vinos del Dâo de la zona de Viseu.

6. ${ }^{\circ} \mathrm{El}$ antiguo y activo poblamiento de estas tierras, ha dado origen a importantes realizaciones no sólo monumentales sino también culturales, como lo ratifica su rico, variado e interesante folclore, artesanía y fiestas populares, que tienen gran arraigo entre la población y creciente aceptación entre los turistas. Los ejemplos que podrían citarse son también numerosos, por lo que mencionaré sólo algunos casos: la Feria de San Mateo en Viseu, Carnavales de Ciudad Rodrigo, Semana Santa y la Feria de Salamanca, entre otros muchos. Todas las fiestas populares, que cuentan con gran abundancia, variedad y arraigo en estas tierras, viven hoy un período de gran auge, por lo que son un importante recurso turístico. En ellas participan con entusiasmo creciente los que viven aquí, pero asisten a las mismas gentes de estas tierras que emigraron y vienen acompañados de familiares y amigos. No obstante su desarrollo aún puede ser mayor y más beneficioso para el sector y la economía de estas tierras. Recuperar estas actividades, mantenerlas con la mayor pureza posible, hacer que arraiguen entre los jóvenes para que no desaparezcan, potenciarlas y darlas a conocer para que atraigan cada día a mayor número de gentes foráneas, debe ser objeto de especial atención por parte de todos y no sólo de los responsables turísticos.

7. ${ }^{\circ} \quad$ Las mejoras en el nivel económico de la población, en parte porque cada vez es más escasa, difusión de una mejor forma de vida, más 
disposición de tiempo libre por reducción de la jornada laboral y semanal, más vacaciones, jubilaciones anticipadas y costumbre creciente de ocupar parte del tiempo libre viajando, reservado esto antes para grupos minoritarios con elevado nivel económico, y las mejoras en las comunicaciones y medios de transporte por carretera, explican la existencia de ciertos servicios, instalaciones y actividades orientadas a ocupar el tiempo libre y de ocio de la población autóctona y ajena. La importancia de esto es creciente hasta el punto de poder considerarlo como un recurso turístico más, a veces con destacada importancia para el lugar o la zona que los tiene y, en general, para el sector turístico, por su novedad e interés. Tal es el caso de las ofertas que se hacen hoy al turista que visita estas tierras, como el interesante y moderno Complejo existente en Viseu, por citar sólo uno de éstos, con instalaciones deportivas variadas y modernas, campo de golf, salas de cine, tiendas de gran calidad y restaurantes, es prueba de la existencia de un importante recurso vinculado a tales actividades.

8. $\quad$ A las modalidades citadas hay que unir el Turismo de Congresos, que en Salamanca tiene destacada importancia y tradición por su actividad universitaria. El Palacio de Exposiciones y Congresos de Castilla y León ha influido muy positivamente en tal sentido por el reclamo que supone su existencia y las buenas instalaciones que posee. También Viseu cuenta con instalaciones apropiadas para este tipo de actividades que constituyen una clientela importante dentro del Turismo de calidad. Creemos que es muy positivo todo lo que se haga por impulsar este tipo de turismo, cuando se cuenta con el atractivo y las instalaciones apropiadas para ello como es el caso de Salamanca. Además de incrementar el número y la importancia de los recursos turísticos, acrecientan la diversidad de la oferta, haciendo posible que sean más los interesados por venir a disfrutar de ellos, con el consiguiente beneficio para la actividad turística de la Ruta E-80: Salamanca-Aveiro. Este tipo de recursos es el que puede incrementarse y mejorarse más, pues depende mucho de la creatividad e inversiones de los reponsables políticos, de los empresarios y de la eficacia en la promoción que se haga para captar más y mejores congresos.

9. ${ }^{\circ}$ Hasta hace escasos años, en las regiones interiores, eran muy pocos los que estaban interesados y participaban en la actividad turística que hoy conocemos como Turismo rural o activo; solían ser los que tenían instalaciones hosteleras, agencias de viaje, guías, algunos estu- 
diosos del tema y pocos más, careciendo de interés para el resto de la población que estaban más atraídos por el turismo de Sol y Playa que por éste. Poco a poco ha ido cambiando esta mentalidad, primero y en mayor cuantía, en las zonas costeras y, después en las zonas y ciudades turísticas interiores como la que se estudia en este trabajo. El interés por el Turismo Rural es cada día mayor entre la gente más heterogénea y algo similar está ocurriendo con los que participan directa o indirectamente en el mismo. Causa y consecuencia de este interés es el incremento y la diversidad de ofertas que se le hacen a los participantes de este tipo de turismo con actividades tales como caza y pesca, senderismo, cicloturismo, agroturismo, paseos a caballo, ecoturismo, etc., y, además, los campos de golf, como el de Salamanca. También está el incremento de las Casas para el Turismo Rural y las Quintas, cada día con más aceptación y clientela en estas tierras, aunque muy lejos aún del límite de sus posibilidades. Todas estas actividades están en auge creciente a lo largo de la Ruta E-80: Salamanca-Aveiro.

$10 .^{\circ} \quad$ Por último no se debe olvidar otro interesante recurso que hace que los anteriores resulten más atrayentes e interesantes a los turistas y que se mantengan o conserven y, sobre todo, que puedan acrecentar su importancia. Se trata del carácter afable, talante humanitario y hospitalidad de las gentes de estas tierras, lejos todavía de la deshumanización, de las relaciones humanas frías y distantes, predominantes ya en otros lugares. Una relación más humana, el trato afable y atento, sin servilismo dado al turista, hace que éstos se lleven mejor recuerdo de su paso por estas tierras y se conviertan en eficaces propagandistas de las mismas. Esto es importante en cualquier relación humana, pero en este caso tiene mayor influencia, sobre todo en el Turismo de Interior, donde la relación con el turista es más directa y estrecha. En la actividad turística, quizás, sea en la que tenga más razón el aplicar la sentencia china que dice «Si no sabes sonreír no abras un comercio.»

El sector turístico de estas tierras está muy lejos de ser una actividad importante dentro de su maltrecha economía, pero puede llegar a serlo, a convertirse en un interesante recurso económico que frene la emigración y que estas tierras recuperen el tono económico perdido y que las sitúa entre las últimas regiones hispanoportuguesas. Para ello se deben dar a conocer y explotar los recursos turísticos existentes en ellas, entre los cuales el talante de la población y no sólo de los que trabajan 
en el sector turístico, es también importante, junto con la riqueza y diversidad del paisaje natural y monumental, la gastronomía o las fiestas populares. Perder o permitir que se deterioren los recursos citados, es apostar claramente por la dècadencia de la actividad turística o ponerle un pesado lastre que no permitirá su desarrollo en la forma, con la intensidad deseadas y como se merece la calidad, diversidad e interés de los recursos turísticos existentes. Para ello es necesario conocer tales recursos, sus características, problemática y posibilidades (Fig. 1).

Características de los recursos turísticos de la Ruta E-80:

Salamanca-Aveiro

La adecuada explotación y aprovechamiento de los recursos turísticos de cualquier espacio, en este caso de los existentes en las tierras de la E-80: Salamanca-Aveiro, y la importancia que puede adquirir la actividad turística en dicho territorio depende, no sólo de la existencia de interesantes recursos, sino también de una serie de características que tienen los recursos citados y que, de alguna manera, a veces bastante influyente, hacen que el sector turístico tenga más o menos desarrollo y que ocurra algo similar en la aportación de dicha actividad a la economía de estas tierras. Señalaré las características que considero más importantes, influyentes y generalizadas en el territorio estudiado en este trabajo. Es fácil señalar otras más, pero carecen de alguno de los rasgos citados antes:

1. ${ }^{\circ} \quad$ La primera y destacada característica es la existencia de recursos turísticos, abundantes, variados e interesantes, que impulsan a las gentes, propias y de otros lugares, a visitarlos para disfrutar con ellos. En el apartado anterior quedó de manifiesto que se trata de unos recursos interesantes, variados, atrayentes y en la cuantía suficiente como para que la actividad que podría montarse con un aprovechamiento mejor, fuera más importante dentro de la economía de estas tierras.

2. ${ }^{\circ} \quad$ La población que vive en las tierras cruzadas por la E-80: Salamanca-Aveiro, presenta unos rasgos que interesa conocer, por su destacada influencia en el sector turístico, por dos motivos, ser los primeros clientes de dicho sector y los que deben impulsarlo y desarro- 
llarlo. Su importancia está devaluada, reducida, por la escasa población que vive a lo largo del tramo citado de la Ruta E-80, por la intensa emigración de los años sesenta, baja tasa de natalidad, alta de envejecimiento y crecimiento natural negativo, con todo lo que esto entraña demográfica, económica y socialmente. Además, tan escasa población y envejecida población absoluta tiene otros rasgos que reducen aún más los potenciales clientes para su propia actividad turística. Tal es el caso del elevado porcentaje de población rural existente aquí, a pesar del intenso éxodo rural. Sabemos que esta población participa menos en todos los aspectos de la actividad turística que la urbana, en igualdad de condiciones. Estos rasgos negativos de la población se ven compensados, en el aspecto turístico, por las cualidades que tienen sus habitantes: afabilidad, hospitalidad y talante humanitario que agradan al turista, sobre todo al procedente de las grandes ciudades o con modos de vida deshumanizados y muy diferentes al todavía predominante en estas tierras.

3. ${ }^{\circ}$ Desaparición de la frontera hispano-portuguesa como factor de separación, aislamiento y, a veces, confrontación entre España y Portugal, lo que impedía las buenas relaciones y actividades entre las gentes de uno y otro lado de la misma. Hoy existe un creciente auge en las relaciones socioeconómicas y actividades conjuntas, para el desarrollo económico y la promoción turística. Es grande y recíproco el interés en conocer las tierras del territorio vecino por unos y otros. En Semana Santa y verano son muchos los salmantinos que visitan Portugal y, sobre todo, las tierras vecinas y muchos fines de semana y en Nochevieja es notoria y creciente la presencia de portugueses en Salamanca. Además, hay un interés recíproco y creciente en realizar actividades similares en otros sectores y a niveles empresariales y universitarios. Hay mucho por hacer en este campo, al ser muchos los intereses comunes y los siglos viviendo de espaldas, de ignorancia recíproca, cuando no de enfrentamiento y sin ninguna o poca colaboración. Este cambio y predisposición recíproca favorable es fundamental y debe ser aprovechado adecuadamente por parte de unos y otros y, en definitiva, en favor del desarrollo turístico de la Ruta E-80: Salamanca-Aveiro.

$4 .^{\circ} \quad$ Incremento del nivel económico hispano-portugués, mejoras en las condiciones de vida de la población de ambos países, lo que ha acrecentado el número de potenciales clientes interesados por los recursos turísticos de estas tierras. Se suele olvidar frecuentemente que en 


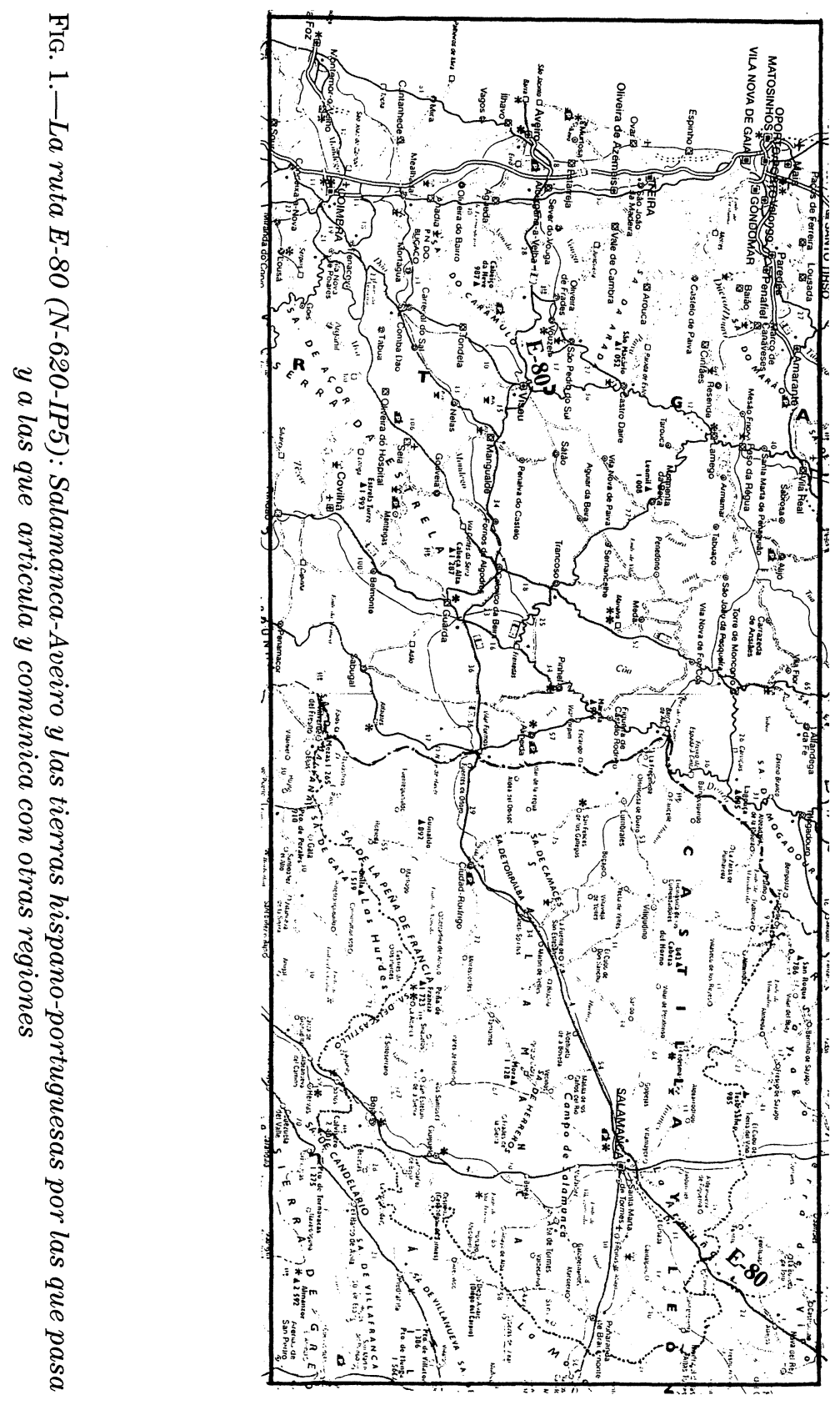

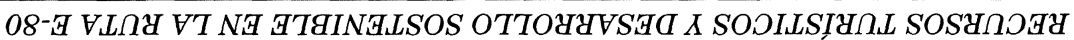


el Turismo de Interior los clientes más importantes son los de la propia región o tierras cercanas.

$5^{\circ} \quad$ Ciertas características geográficas suelen tener una influencia destacada en el sector turístico, por su importancia en el clima, en la diversidad paisajística, pero también el encontrarse en buena posición respecto a otras regiones de las que pueden llegar visitantes. Es lo que ocurre con las tierras de la E-80: Salamanca-Aveiro. Tienen una situación favorable dentro de las tierras peninsulares, en el centroeste de la Península Ibérica lo que, en teoría, le permite tener como potenciales clientes a la numerosa población del N y Centro de España y Portugal: Galicia, Castilla y León, Madrid, Centro de Portugal, Porto y Lisboa. Para que esta ventaja, derivada de su situación, sea una realidad, se tienen que mejorar las comunicaciones para que los visitantes puedan llegar hasta estas tierras y desplazarse por ellas con rapidez, confort y seguridad, lo que hoy no pueden hacer, por las graves deficiencias existentes en las comunicaciones, sobre todo el ferrocarril, con varias líneas cerradas al tráfico y las restantes con pocos y malos servicios.

$6^{\circ} \quad$ La importancia del sector turístico en la economía española, las posibilidades que ofrece el poder impulsar su desarrollo en estas tierras, han hecho que los responsables políticos, empresarios y expertos, presten hoy gran atención a la promoción turística y auge del sector. Está demostrado que puede ser una clara posibilidad para el desarrollo económico de estas tierras y freno a la intensa emigración sufrida en estas tierras y de los que se marcharían, si encontraran dónde, aunque el sector turístico de las tierras de la Ruta E-80: Salamanca-Aveiro y las infraestructuras necesarias para su desarrollo, adolezcan aún de graves deficiencias por causas propias y ajenas.

7..$^{\circ} \quad$ Característica destacada también, y que es un importante factor para el desarrollo del sector, si se aprovecha adecuadamente, es la existencia, el paso por ellas, de un importante Eje de Comunicaciones, formado por una carretera, la E-80 (N-620-IP5) París-Lisboa, y el ferrocarril París-Lisboa que discurren paralelos y uniendo ambas ciudades en la forma más directa. Históricamente ha sido la vía de comunicación terrestre, empleada por Portugal para enlazar con Europa Central. Su importancia está fuera de toda duda, como lo confirman los casi dos millares de vehículos pesados que diariamente pasan por Salamanca en ambas direcciones y los miles de turistas que hacen otro tanto cada año, para dirigirse desde Francia hasta Portugal. Se trata de un Eje que, no 
sólo cruza estas tierras, las articula y contribuye a su desarrollo económico, sino que las relaciona con otras regiones, cuyas poblaciones son potenciales clientes, ya que pueden desplazarse hasta aquí, si se logra interesarles en que lo hagan. Este factor ve muy reducida su influencia por las deficiencias del citado Eje, tanto la carretera entre Tordesillas y Villar Formoso, con el peor tramo entre París-Lisboa, como el ferrocarril, anticuado, obsoleto y con escasos servicios a partir de Medina del Campo y cuyo uso para el transporte de pasajeros, esto es, de potenciales turistas, es testimonial por no decir nulo.

8. ${ }^{\circ} \quad$ Los recursos turísticos conocidos como Turismo de Interior se encuentran hoy en auge creciente y cada día son más los que se decantan por ellos frente a los de Sol y Playa, no sólo en el turismo nacional sino también en el internacional. Sabemos que en las tierras de la E-80: Salamanca-Aveiro, predominan tal tipo de recursos, aunque cuenten con un amplio frente costero, con interesantes playas, adecuado complemento a los variados y atractivos recursos turísticos existentes en la mayor parte de dicho territorio. Es necesario estudiar y conocer bien las características de unos y otros recursos, porque sólo así se puede establecer la política turística apropiada por su promoción y desarrollo.

9. $\quad$ Algo parecido a lo expuesto en el apartado anterior cabe decir respecto al Turismo Cultural. Los recursos turísticos de este tipo en las tierras de la Ruta E-80, lo integran varias ciudades con importantes conjuntos histórico-monumentales, pueblos con interesantes caseríos, manifestaciones culturales, religiosas y lúdicas, muy diversas, actividades como la Semana Santa, festejos populares con raigambre secular como los carnavales y fiestas populares, celebración de Congresos, etc., tienen una gran importancia, aunque les falte aún mucho para alcanzar el grado de aprovechamiento y explotación posible y deseado. Sabemos que esta es otra característica destacada de los recursos turísticos de estas tierras, ignorarla y olvidarla es condenar al más rotundo fracaso cualquier iniciativa para la promoción.

$10 .^{\circ}$ Otra peculiar característica de los recursos turísticos de la E-80: Salamanca-Aveiro, que se convierte en un importante freno para su adecuada explotación y desarrollo, es su dispersión por todo el territorio, agravado por la diversidad de los mismos. Quien quiera conocer y visitar algún tipo de recurso en particular, tiene que hacer, normalmente, largos desplazamientos, cosa poco agradable en la región por las deficiencias en las comunicaciones, en la infraestructura de servicios, 
señalización e información de los recursos. En los últimos años se ha hecho bastante en la corrección de las deficiencias citadas, pero aún queda mucho por hacer.

11. ${ }^{\circ} \quad$ Las tierras cruzadas por la E-80: Salamanca-Aveiro, sufrieron una intensa y generalizada emigración en los años sesenta y setenta, causa de su actual población, elevada tasa de envejecimiento y crecimiento natural negativo desde hace bastantes años. Pero esto puede ser hoy un factor interesante para el sector turístico, cosa que ya ocurre, pues al estar hoy repartidos por toda España, Portugal y también por otros países europeos, son unos interesantes y convencidos propagandistas y difusores de la belleza e interés de los recursos turísticos de estas tierras.

$12 .^{\circ}$ El Turismo se ha convertido hoy en una necesidad social, en algo básico para la mayor parte de la población europea y, también, en una moda y por ello es hoy un fenómeno popular de masas. Dentro del mismo presenta un notable auge el Turismo de Interior, al que pertenecen la mayor parte de los recursos existentes en estas tierras. Conviene tener esto presente y no creer que, por ser escasos los recursos de Sol y Playa, no se puede contar con un sector turístico importante. Suiza y Austria, por ejemplo, no lo tienen, al igual que muchas regiones interiores y sin embargo nadie pone en duda la importancia del sector turístico.

La características de los recursos turísticos de la E-80: SalamancaAveiro citadas, al igual que el tipo de recurso existentes, tienen una destacada influencia en que la actividad turística adquiera mayor desarrollo del que tiene hoy. De ahí el interés por conocer bien unos y otras. Pero hay que pensar que también los podemos encontrar en otras regiones hispano-portuguesas pues la mayor parte no son exclusivos ni únicos de estas tierras, sino que los hay en otras muchas regiones. Pero los citados antes sí son los más importantes, generalizados e influyentes y, además, ayudan a estudiar, conocer mejor y explicar la situación actual del sector, su problemática y las posibilidades existentes. En el territorio estudiado, además de las citadas, hay otras características de carácter local, que pueden ser también importantes, como un paisaje singular, unos productos típicos, un balneario, una playa, un núcleo histórico, un museo, un parador o posada, un festejo popular que acreciente el interés turístico de un lugar sobre los de su alrededor. Conocer tales características y trabajar para que disminuya la influencia ne- 
gativa que pudieran tener algunas y aumentar lo positivo y favorable de otras, es trabajar para que se desarrolle el sector turístico, mejore la maltrecha economía de la zona estudiada y pueda elevarse el nivel y calidad de vida de su escasa y envejecida población.

Problemática del sector turístico en el tramo de la E-80: Salamanca-Aveiro

El grado de desarrollo de la actividad turística en estas tierras está lejos de haber alcanzado el nivel que, por la calidad, variedad e interés de sus recursos se merece. Esto se debe a que muchos de los factores antes citados, no están siendo aprovechados adecuadamente, ni aportan todo lo que pueden y se espera de ellos. También a la existencia de problemas diversos que aquejan y frenan el sector turístico en regiones interiores como ésta, por diversas causas. Al ser escaso el desarrollo del sector, también lo son las ventajas socioeconómicas que aporta a la economía y nivel de vida de la población, muy por debajo de lo esperado y de las posibilidades existentes. Como en el apartado anterior sobre las características, son muchos y diversos los problemas que aquejan y frenan la actividad turística de estas tierras, unos propios y otros ajenos y muy similares a los que podrían señalarse en otras regiones interiores hispanoportuguesas. Estudiar, conocer cuáles son los principales problemas existentes es también necesario y previo, si se quiere impulsar dicho sector de manera racional y eficaz. En muchos casos los problemas del sector turístico se deben al predominio de la influencia negativa de los aspectos citados antes. En otras ocasiones se trata de problemas propiamente dichos que aquejan al sector o deficiencias en muchos aspectos básicos e importantes y que dificultan y frenan su desarrollo. Expondré aquellos problemas que, desde mi punto de vista, están más generalizados y son más influyentes en la actividad turística de estas tierras.

1. ${ }^{\circ}$ Diversidad y dispersión de los variados recursos turísticos existentes, con la consiguiente dificultad para visitarlos y pérdida de interés para muchos turistas por este motivo. Esto se acrecienta por las deficiencias en las comunicaciones para acceder hasta ellos, en la señalización adecuada y necesaria, visita y otros servicios y por lo difícil y costoso que es mantener, con el nivel adecuado, unas y otros. 
2. ${ }^{\circ} \quad$ Competencia con otras muchas regiones hispano-portuguesas que tienen recursos turísticos similares y, a veces, bastante mejor conservados, comunicados, promocionados, y aprovechados turísticamente que los de aquí. Este hecho, lejos de asustar, debe servir como estímulo y pensar que, si en otras regiones, con recursos turísticos similares a los de estas tierras, han logrado un buen desarrollo y ventajas socioeconómicas, no hay motivos para no conseguir aquí lo mismo.

$3 .^{\circ}$ Minifundismo empresarial, predominio de pequeñas empresas familiares en el sector y, muchas veces, elevada edad media de los empresarios. Suelen ser consecuencia de lo anterior, de la diversidad y dispersión de los recursos turísticos y de la escasa ayuda que la administración ha prestado al sector. Todo esto reduce el dinamismo empresarial, la competencia y deseos de modernizar las instalaciones o llevar a cabo las necesarias campañas de promoción. Por tales motivos la competencia que pueden hacer frente a otras regiones y en el mercado turístico se reduce notablemente, los servicios que se ofrecen y prestan dejan, a veces, mucho que desear y causan una impresión poco favorable en los visitantes.

4..$^{\circ}$ Escasa e inadecuada señalización de los recursos turísticos en las principales rutas de acceso a estas tierras y también en las más importantes que las cruzan, tanto en la E-80 como en otras nacionales, N630 y N-501. El viajero pasa por la zona, junto a importantes recursos turísticos monumentales, paisajísticos o de otra índole, sin que se le informe ni tenga noticia de su existencia y proximidad. Las diferencias en este aspecto, entre el tramo de la E- 80 por estas tierras y a su paso por Francia, son evidentes y grandes. Las deficiencias son aún mayores y más graves cuando se trata de las carreteras comarcales. Se debe exigir a la administración correspondiente que corrija esta importante deficiencia que causa tan mala impresión, resta eficacia a cualquier medida y desanima a muchos posibles visitantes.

5. ${ }^{\circ}$ Escaso apoyo y pocas ayudas de todo tipo, sobre todo económicas, legales y promocionales, hasta hace unos años, por parte de la administración, para impulsar el desarrollo del Turismo de Interior, en claro contraste con lo que viene ocurriendo, desde los años sesenta, con el de Sol y Playa que ha recibido todo tipo de ayudas y bendiciones. Esto explica, en parte, las grandes diferencias existentes entre uno y otro. Afortunadamente las cosas están cambiando a todos los niveles, pero 
son muchos los años de ventaja en favor del Turismo de Sol y Playa, por inercia y porque continúa siendo el que aporta más divisas, sigue gozando de más ayuda que el Turismo de Interior, particularmente que el de tierras como éstas, bastante marginadas en todos los campos y niveles por las administraciones de ambos países. El trato dado al sector turístico refleja bastante bien lo ocurrido en los restantes, como lo confirma la intensa emigración sufrida y el que la mayor parte de los jóvenes están con la «maleta preparada» para marcharse en cuanto encuentren la ocasión propicia para ello. El desarrollo del secto turístico puede ser una de las pocas posibilidades existente en estas tierras para paliar o frenar la emigración.

6. ${ }^{\circ}$ Hay que destacar también la frecuente descoordinación y no pocas veces, enfrentamiento entre las diferentes administraciones e instituciones interesadas o con competencias en turismo, discontinuidad con lo que han hecho ya otros antes, así como excesivo personalismo de los responsables de algunas de ellas, que no siempre son expertos en la cuestión ni hábiles gestores, con el consiguiente detrimento para el sector turístico.

7. ${ }^{\circ} \quad$ En relación con esto cabe destacar también, como un importante problema para el desarrollo del sector turístico, la excesiva y mal orientada politización de la actividad y promoción turísticas por parte de algunos políticos. Al ser un tema importante y que, sobre todo, está muy de moda, como los problemas medio ambientales, se aprovechan de esta circunstancia en beneficio personal, aunque sea perjudicial o poco apropiado tal tipo de comportamiento para la actividad turística. Tampoco es bueno, como hacen algunos, considerar el turismo como la panacea para resolver los graves problemas socioeconómicos de territorios deprimidos, con escasa y envejecida población y despoblados, como los de la Ruta E-80: Salamanca-Aveiro. Puede ser un sector que contribuya a mejorar, a paliar, la difícil situación socioeconómica de estas tierras desde hace un cuarto de siglo, pero nunca para solucionar los muchos y difíciles problemas existentes en ellas.

8. ${ }^{\circ}$ Menor interés, por parte de muchos turistas, por los recursos turísticos de estas tierras que por los de Sol y Playa. Aunque la situación ha cambiado bastante respecto a la de hace unos años y el Turismo de Interior tiene cada día más aceptación y clientela, las diferencias entre ambos tipos de turismo aún son abismales. Estos hechos deben ser conocidos, no amilanarse por ello y actuar en consecuencia. 
9. ${ }^{\circ}$ Riesgo de deterioro y pérdida de interés de muchos recursos turísticos de la zona, por ser tantos, tan variados y dispersos y, también, por no prestarles la atención suficiente para su conservación, racional y adecuada explotación de los mismos. Este riesgo es evidente en la riqueza monumental y en la conservación, con las características actuales, de muchos paisajes bastante frágiles y fáciles de alterar. Por eso la explotación de unos y otros requiere una política turística que tenga muy en cuenta las características, peculiaridades y problemática del sector.

$10 .^{\circ} \quad$ Las características de la población propia también constituyen un importante problema para el desarrollo del sector turístico. Como ya se señaló antes en los factores, estas tierras tienen una escasa y envejecida población, a causa de la intensa emigración de los años sesenta, el Crecimiento Natural negativo que ha tenido después, así como su elevada Tasa de Envejecimiento actual, superior al 20\% de su población y entre las más altas de la Península Ibérica y la UE. Estos aspectos, junto con la elevada cuantía de población rural, son un grave inconveniente para el sector turístico, ya que se reducen los potenciales clientes que podría tener entre su propia población, aunque hoy la $3 .^{a}$ edad tenga cada día más importancia como mercado y cliente turístico. Tampoco es una población adecuada para que en ella surja un empresariado joven, dinámico y emprendedor en una actividad nueva como la turística y con escasa tradición en estas tierras.

Los problemas expuestos antes no son exclusivos de esta zona, como tampoco lo son los recursos turísticos y los factores que influyen en el auge del sector. Conocer dicha poblemática turística a fondo, al igual que los factores expuestos antes, es indispensable, condición previa si, de verdad, se desea llevar a cabo una política turística realista, eficaz, que logre que la actividad turística aporte los beneficios socioeconómicos que se espera de los recursos turísticos existentes, impulse el desarrollo del sector, de la economía en general y eleve y mejore el nivel de vida de la población de estas tierras.

\section{Algunas ideas o sugerencias para el desarrollo turístico} de la Ruta E-80

De forma escueta y rápida puede decirse que, para impulsar el auge turístico de las tierras de la E-80: Salamanca-Aveiro, lograr que dicho 
auge sea un Desarrollo Sostenible en la economía de estas tierras, en mayor cuantía y medida que hasta hoy y que no suponga la destrucción de los recursos turísticos existentes, ni el deterioro del medio natural en el que se hallan, bastaría con impulsar la influencia positiva de los factores citados antes, reducir la negativa incidencia que tienen otros y dar la solución adecuada a los problemas existentes. Esto es una excesiva simplificación de un tema bastante complejo e importante. Por ello y, sin entrar en un análisis exhaustivo de la cuestión, por las características del presente estudio, sí considero necesario aportar algunas ideas y señalar posibles soluciones a los problemas existentes que sirvan para conseguir lo fines que se esperan del sector turístico y señalados antes. Como en los apartados anteriores sólo expondré aquellas que tienen una aplicación más generalizada al territorio de la Ruta E-80: Salamanca-Aveiro o pueden aplicarse a varios de los problemas existentes en la misma.

1. ${ }^{a} \quad$ Exigir de las administraciones correspondientes la mejora y modernización de las infraestructuras y servicios relacionados con el sector turístico, para adecuarlos a las exigencias de los tiempos y una demanda cada día mayor y más exigente. Particularmente deficientes, en todos los aspectos y niveles, son las comunicaciones, carretera y ferrocarril, a su paso por estas tierras. Mejorarlas a tono con los tiempos y las necesidades existentes es condición previa, fundamental e imprescindible para hacer que la actividad turística adquiera el nivel de desarrollo que puede y debe tener por los recursos existentes.

$2 .^{a} \quad$ Modernizar, ampliar y completar por todo el territorio las instalaciones de los servicios hosteleros, para que ofrezcan el nivel de calidad adecuado y exigido por los visitantes. Asimismo se debe llevar a cabo, con urgencia y eficacia, la señalización adecuada de los recursos turísticos en las carreteras y ferrocarriles de acceso y a lo largo de las carreteras principales dentro de la región. Difícilmente se puede visitar algo si no se sabe de su existencia, aunque se pase a su lado.

$3 .^{a} \quad$ Conseguir que la administración, en sus diferentes niveles, preste más ayuda económica al sector, haciendo después el seguimiento adecuado a tales inversiones para que cumplan los objetivos previstos: impulso y desarrollo del sector turístico.

$4 .^{a}$ Impulsar la coordinación recíproca y desde todos los puntos de vista, de las diversas administraciones con competencias turísticas, así como con los empresarios y expertos del sector, en los aspectos ci- 
tados antes. Convencerse y actuar en consecuencia de que la unión hace la fuerza. Es necesario que desaparezca el personalismo e ineficacia de algunos responsables de instituciones, que tengan en cuenta la opinión de expertos y no se tire por la borda lo que otros han hecho bien antes, para volver a empezar de cero.

5. ${ }^{\text {a }}$ Estimular, involucrar y exigir a los empresarios para que modernicen sus instalaciones, mejoren los servicios existentes, introduzcan otras nuevas como el golf y complejos polivalentes para el ocio urbano, como el existente en Viseu, por ejemplo. Que colaboren con la administración realmente y no se limiten a recoger el fruto del esfuerzo realizado por los demás en la promoción del sector. Exigir a los empresarios del sector turístico, a sus Asociaciones, un mayor compromiso de colaboración real, efectiva y más desinteresada en las promociones turísticas, en los precios y en la mejora de los servicios hosteleros y de atención al turista, ya que son ellos los primeros en obtener ventajas y beneficios del desarrollo turístico que se consiga. Deben dejar de lado el comportamiento que han tenido muchas veces hasta ahora, que sean otros los que les saquen las castañas del fuego.

$6 .^{a} \quad$ Fomentar las mejoras en la formación profesional del personal ocupado en las profesiones relacionadas, directa o indirectamente, con la actividad turística: hostelería, agencias de viaje, oficinas de información y promoción turística, para que presten un buen servicio en beneficio de los visitantes y del sector.

7. ${ }^{a} \quad$ Incrementar las ayudas, subvenciones económicas y las medidas legales y educativas, encaminadas a proteger, recuperar y conservar los recursos turísticos que pueden deteriorarse por su explotación y el paso del tiempo, para que cumplan los fines que se espera de ellos y en el Desarrollo Sostenible de estas tierras.

8. ${ }^{\text {a }} \quad$ Llevar a cabo una promoción turística de las tierras salmantinas y de las Beiras, realista, eficaz, apropiada a los recursos existentes y a los tiempos actuales y conscientes de la importancia real que tiene la actividad turística para mejorar la economía y el nivel de vida de la población. Para ello se debe implicar a todas las partes interesadas, instituciones públicas y privadas, empresarios del sector y expertos o estudiosos del tema. Además, se debe hacer ambién la promoción adecuada en los territorios y ciudades con población, posibilidades e interés en visitar estas tierras. Mercados donde se sabe que hay más potenciales clientes, como son las grandes ciudades hispano-portuguesas 
y regiones con niveles económicos y culturales altos, no lejanas de aquí, y en las que el interés Turismo de Interior, predominante en estas tierras, se halla en auge.

La eficacia y resultados de esta promoción, al igual que los resultados, se incrementarían si se hace conjuntamente por todas las instituciones de la Ruta E-80 existentes a uno y otro lado de la frontera. Sabemos que las tierras portuguesas de la Ruta tienen una clientela importante entre los salmantinos y a la inversa. Pero la cuantía real de estas corrientes turísticas es escasa, en buena medida, por el desconocimiento recíproco. Por este motivo y porque la unión de esfuerzos contribuirá a mejorar los resultados, es por lo que se deben impulsar las relaciones de todo tipo y a todos los niveles, entre gentes e instituciones hispano-portuguesas de la Ruta.

9. ${ }^{a} \quad$ Consecuencia de lo anterior, debe ser la realización de actividades conjuntas concretas, encaminadas a impulsar la promoción y el desarrollo general y turístico de estas tierras. Se debe aprovechar para ello la existencia de instituciones como el Instituto Luso-español de Salamanca, la Mesa de Ciudades de la IP5, una Ruta para Europa, Consulado de Portugal en Salamanca, Asociaciones empresariales existentes a lo largo de la Ruta, empresas salmantinas establecidas en Portugal y las portuguesas que trabajan en Salamanca, y de otras Instituciones como las Universidades y entidades financieras, interesadas todas en promover el desarrollo socioeconómico de estas tierras y, dentro del mismo, el de la actividad turística.

En relación con este aspecto, sería interesante realizar Seminarios, Jornadas, Reuniones de Trabajo sobre temática turística, con la participación de expertos y responsables políticos, españoles y portugueses. Estarán encaminadas a estudiar y dar a conocer las características y problemas del sector turístico, para que los responsables los conozcan y tomen las medidas oportunas para su solución y desarrollo del sector. Asimismo se deben editar guías, folletos y trípticos turísticos explicativos sobre la zona, en portugués y español, de los recursos turísticos existentes a lo largo de la E-80. Esta documentación debe ser repartida en las oficinas de turismo y agencias de viaje de estas tierras y también, en las promociones turísticas que unos y otros hagan en cualquier lugar, conjuntamente o por separado.

$10 .^{a} \quad$ La unión de todos los relacionados con la actividad turística y el apoyo de los responsables de instituciones públicas y privadas, debe

$$
-297-
$$


servir para incrementar las ayudas y subvenciones al sector turístico procedentes de las diversas administraciones y de fondos de la UE. Tales ayudas no deben limitarse al sector hostelero, sino también al de la artesanía, conservación, restauración y rehabilitación de monumentos, pueblos y paisajes, actividades culturales, productos típicos, ciertos cultivos, fiestas populares tradicionales, para que no se pierdan e incluso para su recuperación. De esta manera las ventajas del auge turístico beneficiarían a más gente, contribuirían a mejorar la maltrecha economía de estas tierras, frenarían la emigración de jóvenes e, incluso, podrían fomentar el retorno de algunos que se han tenido que marchar y la actividad turística adquiriría el verdadero sentido de Desarrollo Sostenible, esto es, explotar los recursos existentes de estas tierras de forma racional, integral, en beneficio de todos y sin poner en peligro su continuidad futura. Sólo con estos objetivos y desde las premisas citadas se puede conseguir impulsar el desarrollo de la actividad turística y ser ésta un importante factor de desarrollo.

\section{Conclusiones}

Tras el estudio de los aspectos generales de la actividad turística en la Ruta E-80: Salamanca-Aveiro, el conocimiento de los principales recursos existentes en ella, las características que presentan éstos, los problemas que dificultan un mayor desarrollo y las sugerencias para contribuir a conseguir éste, es fácil señalar una serie de conclusiones para concluir este trabajo realizado desde la perspectiva geográfica y cuya finalidad era estudiar y dar a conocer los aspectos antes citados.

1. ${ }^{\text {a }}$ La actividad turística presenta hoy un gran desarrollo a escala mundial; España está entre los tres primeros países del mundo por el número de visitantes e ingresos obtenidos por la misma. Desde los años sesenta ha sido y es el recurso de Sol y Playa el más importante, pero hoy también tienen destacada y creciente importancia los recursos conocidos como Turismo de Interior que son muchos, variados, interesantes y en auge creciente en cuanto a la aceptación que tienen.

$2 .^{a} \quad$ El auge del Turismo de Interior y las dificultades por las que pasa la economía en muchas regiones interiores, con escasa y envejecida población, ha hecho que se vea la explotación de sus recursos turísticos, 
como una interesante posibilidad para mejorar la difícil situación socioeconómica en la que se encuentran.

$3 .^{a} \quad$ Esto es lo que sucede en las tierras por las que pasa la E-80 (N620-IP5): Salamanca-Aveiro. Tienen recursos turísticos variados, interesantes, con importantes ciudades histórico-monumentales, paisajes de gran belleza y diversidad en sus montañas, tramos fluviales de gran interés y belleza por su encajamiento, gastronomía, arquitectura rural, fiestas populares, etc., con predominio de los de Turismo de Interior, no faltando un interesante frente costero con interesantes playas.

$4^{\text {a }} \quad$ La explotación de tales recursos turísticos tropieza con muchos y serios problemas que dificultan el adecuado aprovechamiento de los mismos. Tal es el caso de su abundancia, diversidad y dispersión territorial, graves deficiencias en las infraestructuras viarias, hosteleras, promocionales, de señalización y de las inversiones necesarias para solucionar tales problemas. Asimismo, el minifundismo empresarial, la competencia con otras regiones españolas que tienen recursos similares y ya mejor organizadas en su explotación y la escasa coordinación entre los responsables de instituciones e interesados por el sector, son otros tantos problemas que tendrán que solucionarse, si se quiere que la actividad turística en las tierras de la E-80: Salamanca-Aveiro, aporte a la economía de estas tierras lo que se espera y puede alcanzarse de ella y registre el grado de desarrollo que por la calidad e interés de sus recursos se merece.

$5 .^{\mathrm{a}} \quad$ La primera y fundamental condición para lograr el desarrollo deseado de los recursos turísticos de estas tierras, es tener el adecuado y actual conocimiento de los mismos, sus características y los principales problemas que aquejan el sector y frenan su desarrollo. Este ha sido el objetivo prioritario en la realización del presente trabajo, consciente de que sólo cuando se conocen bien los aspectos antes citados de un determinado tema se puede actuar con eficacia. De lo contrario resultarán ineficaces muchas inversiones que se realicen y esfuerzos que se hagan.

$6 .^{a} \quad$ Para impulsar el desarrollo del sector turístico en estas tierras, interesa, también, superar todo protagonismo personal, unir esfuerzos de todas las instituciones e interesados, a todos los niveles y a uno y otro lado de la frontera. Lograr que se subsanen pronto las deficiencias existentes no sólo en el sector sino en otros de estas tierras vitales para su desarrollo, como son las comunicaciones. 
7. ${ }^{\mathrm{a}} \quad$ Si se consiguiera lo anterior, el sector turístico podría ser en las tierras de la E-80: Salamanca-Aveiro, una actividad con más peso e importancia de la que hoy tiene en su maltrecha economía. Además, si se realiza su explotación turística adecuada y racionalmente sería, también, una baza muy importante para lograr eso que ahora todo el mundo persigue o por lo menos no hacen más que referirse al mismo el Desarrollo Turístico Integral y Sostenible, es decir, explotar los variados recursos turísticos existentes, y otros que son complementarios y necesarios para lo anterior, de forma racional, sin deteriorar ni destruir los recursos ni el medio natural en el que se encuentran, para que lo puedan seguir haciendo también, y de manera similar, las generaciones futuras. Ese es también el objetivo primordial y prioritario que impulsó la realización de este trabajo. Si se ha conseguido avanzar algo en tal sentido me doy por muy satisfecho.

\section{BIBLIOGRAFÍA}

Anton, S. y GónZaLEz, F. (1997): «Opciones del Turismo para el desarrollo sostenible en los espacios rurales», en Turismo de Interior. AGE, Madrid, pp. 61-70.

BACHILLER MARTínez, J. M. a (1997): «Turismo y desarrollo rural en España», en Turismo de Interior. AGE, Madrid, pp. 617-26.

BAYÓN VERAS, S. (1997): «Características específicas de los productos del Turismo de Interior y situación actual del Turismo de Interior en España», en Turismo de Interior. AGE, Madrid, pp. 81-92.

BRANDIS, D. y Río DEL I. (1995): «Turismo y Medio Ambiente en las ciudades históricas», Anales de Geografía de la Universidad Complutense, n. ${ }^{\circ}$ 15, pp. 157-168.

BRown GonZÁLEZ, G. (1995): «La educación para el desarrollo sostenible del turismo», III Jornadas de Geografía del Turismo. AGE, Palma de Mallorca, pp. 19-29.

Bull, A. (1994): «La economía del turismo». Alianza Edit., Madrid.

Callizo Soneiro, J. (1991): «Aproximación a la Geografía del Turismo». Edic. Síntesis. - (1997): «Potencialidades turísticas de las áreas interiores. Conflictos y cautelas», en Los turismos de interior, AGE, Madrid, pp. 17-60.

CAMPESINo FERnÁNDEZ, A. J. (1997): «El turismo en la política de cooperación transfronteriza lusa-extremeña», en Turismo de Interior. AGE, Madrid, pp. 627-42.

CASILlAS BUENO, J. C., y otros (1995): «El turismo alterantivo como un sistema integrado: consideraciones sobre el caso andaluz», Rev. Estudios Turísticos, n. ${ }^{\circ} 125$, pp. 53-75.

Corrales Bermejo, L. (1993): «Apuntes para la definición y concepto de turismo rural», Rev. Andanzas. Escuela Regional de Turismo, Ávila.

Díaz Álvarez, J. R. (1988): «Geografía del Turismo», Edic. Síntesis, Madrid.

Figuerola Palomo, M. (1986): «Tendencias y problemas del turismo actual», Rev. Estudios Regionales, n. ${ }^{\circ}$ extraordinario, vol. VI, pp. 17-40, Madrid.

- (1992): «El turismo y su evolución en la última década. Perspectivas para el año 2.000», Rev. Estudios Turísticos, n. ${ }^{\circ}$ extraordinario, pp. 3-22.

$$
-300-
$$


GARCíA ZARZA, E. (1994): «Recursos turísticos de la Ruta de la Plata. Importancia y aprovechamiento", Conferencia Inaugural, LVIII Asamblea Nacional de CIT. Salamanca.

— (1994): Paisajes y pueblos de Castilla y León. Edic. Lancia, León.

- (1995): «Ordenación territorial turística de Castilla y León», Actas del Congreso de Turismo Rural de Castilla y León, Ávila, pp. 87-99.

- (1995): Pueblos y paisajes salmantinos. Asoc. Antiguos Alumnos de la Universidad de Salamanca. Salamanca.

_ (1996): La Ruta del Duero. Junta de Castilla y León. Edilesa. León.

_ - (1997): «Las Arribes. Rutas Turísticas Provinciales», Junta de Castilla y León. CIT Salamanca.

(1997): «Las edades del hombre en Castilla y León. Un caso singular de Turismo Cultural», en Los Turismos de Interior. AGE, Madrid, pp. 431-47.

- (1997): Salamanca. Un museo en la calle. Folleto-Guía. Junta de Castilla y León. CIT, Salamanca.

- (1998): «Recursos turísticos y población rural en Castilla y León. Una alternativa para su desarrollo", Actas de Jornadas sobre "Ecoturismo y población rural en Castilla y León». Fundación para el Progreso Social, Salamanca, pp. 73-134.

- (1998): «Paisajes y pueblos del Camino de Santiago palentino. Difusión de una imagen paisajística monótona, triste y fea», en Libro Homenaje al P. Velicia. Publicaciones de Caja Duero. En prensa.

GIRARDET, H. (1992): Ciudades. Alternativas para una vida urbana sostenible. Celeste Edic. Madrid.

GotARRODONA, R. y RIPOLL, A. (1995): «El turismo alternativo en Mallorca», III Jornadas de Geografía del Turismo, Palma de Mallorca, pp. 203-215.

HúESCAR, A. (1993): «Nuevo marco conceptual del turismo», Rev. Estudios Turísticos, n. ${ }^{\circ}$ 117, pp. $23-48$.

Junta De Castilla y León (1994): Actas del II Congreso Regional de Turismo de Castilla y León. Valladolid.

LANQUART, P. (1992): «Le tourisme de santé», Re. Espaces, n. ${ }^{\circ} 17$. París.

LECO BerRoCAL, F. (1997): «Potencialidades turísticas de las dehesas extremañas: la actividad cinegética», en Turismo de Interior, pp. 161-69. AGE, Madrid.

Lozato-Giotart, J. P. (1992): Geografía del turismo. Edic. Masson. Barcelona.

MARCHENA GóMEZ, M. (1995): «El turismo metropolitano: una aproximación conceptual», Rev. Estudios Turísticos, n. ${ }^{\circ} 126$, Madrid, pp. 7-21.

NoGue i Font, J. (1989): «Paisaje y turismo», Rev. Estudios Turísticos, n. ${ }^{\circ} 103$, pp. 25-40.

OMT (1995): Previsiones del Turismo Mundial hasta el año 2000 y después, FITUR.

O'HAGAN, J. (1992): «Significación económica del turismo en la Comunidad Europea», Rev. Estudios Turísticos, Madrid, pp. 29-40.

PenAs MuRIAS, M. V. (1997): «El turismo rural en Galicia: una estrategia territorial para la revitalización económica», en Turismo de Interior. AGE, Madrid, pp. 561-570.

PÉRez MARTín, M. L. (1995): «Turismo y Espacios Naturales en Extremadura y el Alemtejo», III Jornadas de Geografía del Turismo. Palma de Mallorca, pp. 249-255.

- (1997): «El turismo de la ciudad de Cáceres. Otras opciones al turismo histórico-artístico», en Turismo de Interior, pp. 233-48. AGE, Madrid.

Pillet CAPDEPON, F. (1997): «El Turismo de Interior como nueva fase de desarrollo local», en Turismo de Interior. AGE, Madrid, pp. 249-260.

Priestley, G. K. (1997): «El Turismo de Interior en el conjunto de España», en Turismo de Interior. AGE, Madrid, pp. 261-70.

Priestley, G. K. y SABI, J. (1995): «Una modalidad turística en auge: el golf», III Jornadas de Geografía del Turismo. Palma de Mallorca, pp. 255-267.

Py, P. (1996): Le tourisme. Un phenomène économique. Notes et Etudes Documentaries, n. ${ }^{\circ}$ 5029. La Documentation francaise. París. 
SERRA Busquets, S. (1995): «Turismo y Cultura en las Islas Baleares. Realidad histórica y perspectivas», III Jormadas de Geografía del Turismo. Palma de Mallorca, pp. 299-307. VAN DE BORG, J. (1995): «El turismo y las ciudades artísticas: el caso de Venecia», Rev. Estudios Turísticos, n. $^{\circ}$ 126. Madrid, pp. 79-90.

Vera Rebollo, F. (1993): El futuro en Europa del turismo de ciudades. UIMP. Sevilla. - y DÁvila LinaRes, J. M. (1995): «Turismo y patrimonio histórico cultural», Rev. Estudios Turisticos, vol. 126, pp. 161-177. 